\title{
Testing the Weak Form Efficiency of Palestine Exchange
}

\author{
Sami N. M. Abushammala \\ Msc. Financial Management \\ Lecturer in the University College of Applied Sciences \\ P.O. Box: 1415, Gaza - Palestine \\ Tel: 97-059-948-7497Ｅ-mail: sshammala@ucas.edu.ps
}

Received: June 17, 2011

doi:10.5539/ijef.v3n6p244
Accepted: June 30, 2011

Published: November 1, 2011

URL: http://dx.doi.org/10.5539/ ijef.v3n6p244

\begin{abstract}
Although the Palestine Exchange (PEX) is an emerging market, it proved its excellence to many of the financial markets in the Middle East. Because of the importance of the market efficiency, it is necessary to be tested in order to be sure of equivalent chances. In this research, the Researcher tested the efficiency by using the daily prices at the period from January $1^{\text {st }}, 2007$ to December $31^{\text {st }}, 2010$. The research aims to test the efficiency of (PEX) to make sure that all investors have the same chances in profit taking, and to research the stationary and random walk of PEX Indices. It covered the daily prices of general index in addition to Al-Quds index, also to increase the accuracy of the results, the Researcher tested efficiency of the main sectors Indices of (PEX) is (industry, banking, insurance, services, and investment). The Researcher through statistical measures; Agument Dickey fuller (ADF), the Phillips Perron (PP), and the Kwiatkoowski-Phillips-Schmidt-Shin (KPSS) proved the inefficiency of the (PEX) in the weak level, which means the possibility of taking advantage of technical analysis to be able to predict future prices by extrapolating the past prices.
\end{abstract}

Keywords: Weak form efficiency, Palestine exchange, Unit root

\section{Introduction}

Financial market concept is derived from the concept of the market in general, it has been known since the ancient times, but the foundations and rules have changed over the course of time depending on the economic developments, social changes, the needs of individuals and technological development in the modern era (Mishkin and Eakins, 2009). It is not confide to a spatial framework only, it can be found as long as the effective tools of communication between the sellers and the buyers exist as well. More over, modern markets have tended to specialize in the types of investment, and their instruments (Besley and Brigham, 2003). Although the stock market is relatively recent compared to other commodity markets, it preceded the other markets, both in terms of organization, capabilities and facilities available to the dealers due to the large financial investment to be exchanged in these markets (Mattar, 2001). The debate about efficient markets has resulted in many of empirical studies attempting to determine whether specific markets are in fact "efficient". As a matter of fact, the majority of studies of technical theories have founded strategies which are completely useless in predicting the securities prices. Although transactions' costs may reduce or eliminate any advantage, the researchers have documented some anomalous technical analysis, that may offer some hope for technicians. Many specialists believe that the markets are neither perfectly efficient nor completely inefficient. All markets are efficient to a certain extent, but some of them are more efficient than others. Government bond markets, for instance, are considered to be extremely efficient. Most researchers consider large capitalization stocks are very efficient, while small capitalization stocks and international stocks are considered by some to be less efficient. Real estate and venture capital, which do not have fluid and continuous markets, are considered to be less efficient because different participants may have varying amounts and quality of information (Treynor, 1981). Efficient Market Hypothesis (EMH) which is originally ascribed to Fama (1965), decides that an efficient market prices always fully reflect available information. The (EMH) is associated with the idea of a "random walk," which is a price series where all subsequent price changes represent random departures from previous prices. The logic of the random walk idea is that if the flow of information is unimpeded and information is immediately reflected in stocks prices, then tomorrow's price change will reflect only tomorrow's news and will be independent of the price changes today. An efficient' market is the market where: There are large numbers of rational, profit-maximizers actively competing, all rational profit-maximizers are trying to predict future market values of individual securities, all important current information is almost freely available to all participants, competition among many intelligent participants are prominent characteristics. At any point in time line, actual prices of individual securities have 
already reflected the effects of information based both on events that have occurred and on events which are running now (Fama,1965). (Efficient Capital Markets) the influential survey article by Eugene Fama's (1970), has proved the $(\mathrm{EMH})$, which received widely acceptance among the academic financial economists. It was believed that securities markets were extremely efficient in reflecting information about individual stocks and about the stock market as a whole. The accepted view is that when information arises, the news spreads very quickly and incorporates into the prices of securities without any delay. The hypothesis has three forms of market's efficiency: Weak tests (How well do past returns predict future returns?), semi-strong (How quickly do security prices reflect public information announcements?), and strong form (Do any investors have private information that is not fully reflected in market prices?) (Fama, 1991). Thus, neither technical analysis, nor fundamental analysis, help investors to select "undervalued" stocks, would enable an investor to achieve returns greater than those that could be obtained by holding a randomly selected portfolio of individual stocks with comparable risk (Malkiel, 2003). "If academics are just saying that (EMH) means the market is hard to outsmart, then, no, it has not been discredited at all. But if academics are saying that (EMH) means markets behave rationally, then they do not have good explanations for what went on the past couple of years" (Fox, 2009). Fama and French (1992) concluded that size and price-to-book-value together provide considerable explanatory power for future returns and once they are accounted for, little additional influence can be attributed to P/E multiples. Fama and French (1997) also concluded that the $\mathrm{P} / \mathrm{BV}$ effect is important in many world stock markets other than the United States. If markets are efficient, the serious question for investment professionals is what role can they play and be compensated for. Those that accept the EMH generally reason that the primary role of a portfolio manager consists of analyzing and investing appropriately based on investors' tax considerations and risk profile. Optimal portfolios will vary according to factors such as age, tax bracket, risk aversion, and employment. The role of the portfolio manager in an efficient market is to adapt a portfolio to those needs, rather than to beat the market (Harel, et al,2011). While proponents of the EMH don't believe that it is possible to beat the market, some believe that stocks can be divided into categories based on risk factors and correspondent to higher or lower expected returns. Efficiency of equity markets has important implications for the investment policy of the investors. If the equity market in question is efficient researching to find miss-priced assets will be a waste of time. In an efficient market, prices of the assets will reflect markets best estimate for the risk and expected return of the asset, taking into account what is known about the asset at the time. However, if the markets were not efficient, an investor will be better off trying to spot winners and losers in the market and correct identification of miss-priced assets will enhance the overall performance of the portfolio. EMH has a twofold function - as a theoretical and predictive model of the operations of the financial markets and as a tool in an impression management campaign to persuade more people to invest their savings in the stock market (Venkatesan, 2010). The understanding of efficiency of the emerging markets is becoming more important as a consequence of integration with more developed markets and free movement of investments across national boundaries. Traditionally more developed Western equity markets are considered to be more efficient. Contribution of equity markets in the process of development in developing countries is less and that resulted in weak markets with restrictions and controls (Gupta, 2007). Many studies proved that market is inefficient such as Coin-Flipping, Graham, and Doddsville in A Stock Market Scam who argue that unexpected performance by one or more participants in a market signifies an inefficient market, it is important to recognize that successful active managers should be evaluated in the context of all participants. It is difficult in many cases to determine whether unpredicted performance can be attributed to skill or luck. Also in the article of Cherry-Picking, "Do Past Winners Repeat?" proved that there is no correlation between strong performers from one period to the next proved in number of studies. There is another evidence in support of the EMH which is the lack of consistent performance persistence among active managers. Critics of the EMH have cited that there have been many cases of illogical stock market reactions to various announcements or conditions. There have also been many cases where investors have traded the wrong stock following news. In the article "Using Behavioral Finance to Better Understand the Psychology of Investors,2010" Professor Robert Shiller has even gone so far as to say "The (EMH) is one of the most egregious errors in the history of economic thought." In the same article Andrew Lo (who proposed the Adaptive Markets Hypothesis, in which markets are neither efficient nor irrational, but some combination of both) states "There are periods when the market is highly efficient, and there are those that are not, but there are some implications of market efficiency for a firm's financial decisions as an efficient market has no memory, stock prices follow a random walk, in which the odds of gain or loss tomorrow do not depend in the past changes, so that managers cannot time security issues advantageously unless they have information the rest of the market does not. Moreover, because there are no financial illusions, managers cannot fool the market simply by manipulating accounting data.(Brealey, et al, 2001). One of the most important goal of efficiency is the fair prices of stocks and indices, that must be achieved in any market. That will happen only when stocks and indices succeed in reflecting the new news quickly and in the right direction, that will give all investors the same chance of earning profits. This 
research designed to test the efficiency of Palestine Exchange (PEX) in the last four years at the weak form, in case of study the possibility of making abnormal returns by using the technical analysis, specially after the new platform trading station. Palestine Exchange (PEX) was founded in 1995. The (PEX) was the first Arab Stock Exchanges to be fully automated. The principles of transparency and good governance leads (PEX) to become a public shareholding company in February 2010, under the supervision of the Palestinian Capital Market Authority. After signing the agreement of operating the securities market, as a joint stock company with the Palestinian National Authority in November,7, 1996, the idea of the businessmen was achieved. The market held its first trading session in February 18, 1997 and was the first Arab market to utilize electronic and automated trading of financial securities. In spite of its humble beginning, it has continuous growth in terms of number of the listed companies, meetings and volumes. Starting from a small number of listed companies in early 1997, the number rose to 46 companies in 2011 ( Bulletin Of Palestine Securities Exchange). The main index of (PEX) is AL-Quds index it contains 12 companies, three from banks sector, three from investment sector, three from services sector, two from industry sector, and one from insurance sector, that companies listed in the table (1). In 2009, the (PEX) ranked thirty third amongst the worldwide security markets, and regionally comes the second in terms of investor protection. The (PEX) strives to provide an enabling environment for trading that is characterized by equity ,transparency and competence, serving and maintaining the investors' interest. In PEX there are 46 listed companies with market capitalization of about $\$ 2.5$ billion across five main economic sectors; banking, financial services, insurance, investments, industry, and services (www.pex.ps).

After the recent global financial crisis, with questions about the resilience of the financial system, and talk about the need to reform the global financial system, specially with the ease of technical analysis of the (PEX) through the new trading platform. The research would like to test the efficiency of (PEX) in order to make sure that small investors will not be a victim to the technical strategies which designed by the large investors, and the problem of the research can be summarized in the following main question: Is Palestine Exchange market efficient in weak form?. Many studies aimed to test the efficiency.

\section{Literature Reviews}

There are numerous researchers over the past few decades that have tested the weak form efficiency. In a classic review article on efficient markets Eugene, and Fama (1991) explained what it means to have efficient markets, reviewed the literature on the efficient markets, discussed the various hypotheses on efficient markets, and anomalies. The paper also redefined the common definitions of efficient markets and investigates the joint-hypothesis problem, the costs of information, and various pricing models. This is the second review work on Market efficiency (hence II). The first was written in 1970. Any investigation of market efficiency has at least two problems: the first that information and transaction costs, the second the joint-hypothesis problem. Fama immediately introduces the problem of information costs: "A precondition for this strong version of hypothesis is that information and trading costs, the costs of getting prices to reflect information, are always zero As there are surely positive information and trading costs, the extreme version of market efficiency is surely false." However, this extreme view has an advantage in that it is "a clean benchmark." Fama then says he will use the extreme view and let readers decide on the information and transaction costs. In Palestine Falojey (2005) located out several significant results. One of the most important findings of the research is the unfairness of the PSEM at the first fairness checking level. Likewise, the research recommended several important recommendations. Mainly, the significance of achieving full transparency of published information on stocks by stock shareholders companies. Moreover, the research recommended that the PSEM should improve its Information and communication systems. A study by Gan, et, al. (2005) aimed to re-examines the market efficiencies in New Zealand Stock Exchange (NZSE) and Australia Stock Exchange (ASX) stock indices to investigate whether Groenewold's [1] findings still hold in the period after financial liberalization (January 1990-January 2003). The study also examined whether the larger US NYSE and Japanese NIKKEI stock indices had any influence on the NZSE and ASX indices. Similar to Groenewold's findings, the Researchers found evidence of weak form efficiency for NZSE and ASX stock indices using the Augmented-Dickey Fuller and Philip- Perron unit root tests. In contrast to Groenewold's findings, the Engle-Granger co-integration test results suggested that the NZSE stock index is co-integrated with and granger caused by the ASX index, both violating the semi-strong form market efficiency of NZSE. Although the NZSE is a small stock market, it was stock index was relatively independent with respect to the NYSE and NIKKEI stock indices. Gupta, and Basu (2007) tested the weak form efficiency in the framework of random walk hypothesis for the two major equity markets in India during the period from 1991 to 2006 . The evidence suggested that the series did not follow random walk model and there was an evidence of autocorrelation in both markets rejecting the weak form efficiency hypothesis. Islam and Khaled (2005), found evidence that the Dhaka Stock Market (DHA) returns behaved differently before and after the 1996 stock market crash. Predictability of stock returns seemed to 
characterize the period after the 1996 crash, while after these events; DHA returns have followed a random walk. On the other hand Miclaus, et, al. (2008) tested the AR(1)- GARCH(1,1) model on these young markets and analyzed the impact of National Allocation Plans announcements on carbon prices, by applying an event study methodology using daily carbon futures returns. they found that markets are not efficient as far as the correlation test was concerned; nonetheless, the event study proved that, even if past returns reacted to VER announcements, the expectation building had been functioning correctly since investors were able to predict the market dynamics. The study by Moldovan (2008) presented the results of testing the existence of information efficiency in the Romanian stock market, taking into consideration the financial market efficiency theory [1] as an important factor in the investment decision process. He focused on testing a weak form of market efficiency by analyzing the daily evolution of the Romanian BET-FI index for 8 years. His findings demonstrated the absence of the weak-form of efficiency and the predictable characteristic of the market. While Olowe (2002) tested the hypothesis of weak form efficiency on the monthly stock prices of 59 Nigerian companies by using autocorrelation function test. Results showed that security returns were independent, in other words the Nigerian stock market seemed to be efficient in a weak form. Finally Onour (2009) paper some of statistical tests were applied on individual and sectored price indices, as well as on the aggregate price index of Saudi Stock Exchange Market. The results of the tests rejected the hypothesis of the random walk at all levels of stock price indices. Venkatesan (2010) paper investigated the Random Walk behavior of stock market returns of India. The naïve random walk model was estimated using Ordinary Least Squares method over the period 1st January, 2008 to 31st December, 2009. The data are obtained from the National Stock Exchange (NSE) website, Mumbai. The study result revealed that the return series is insignificantly different from zero, which is consistent with the random walk hypothesis. The study suggested that the Indian stock market is found to be efficient and supports the random walk behavior. All previous studies dealt with the efficiency of financial markets, the most recent studies, specially in weak form proved contrast to of what (EMH) proved, especially in emerging markets.

\section{Research Methodology}

\subsection{Research Sample}

The daily series obtained from (PEX) website for the purpose of collecting in order to examine the questions of the research, test hypotheses and explore the results in order to reach significant values and indicators supported by SPSS, and Eviews programs. The study sample included all indices which contains all the companies listed on the (PEX), the sample comprises of the (45) companies divided in (7) main indices. The sample-selection procedure is summarized in Table (2).

Research Hypothesis

The research posed main null hypothesis, which aims at measuring the of testing the efficiency of the (PEX) to make sure that all investors have the same chances in profit making, and to testing the random walk of (PEX) in order to increase the protection of investors in (PEX). The hypotheses are the following:

H0: The (PEX) is an efficient market.

The Researcher would like to test the hypothesis above by testing the following sub-null hypotheses:-

H01: The daily series of the General index prices have a unit root.

H02: The daily series of Al-Quds index prices have a unit root.

H03: The daily series of the Industry sector index prices have a unit root.

H04: The daily series of Banking sector index prices have a unit root.

H05: The daily series of the Investment sector index prices have a unit root.

H06: The daily series of the Services sector index prices have a unit root.

H07: The daily series of the Insurance sector index prices have a unit root.

\subsection{Research Models}

Before exploring the modes of research we must classify the types of Non-stationary Processes in order to select the suitable tests of random walk the first is Pure Random Walk $(\mathrm{Yt}=\mathrm{Yt}-1+\varepsilon t)$ random walk predicts that the value at time " $t$ " will be equal to the last period value plus a stochastic (non-systematic) component that is a white noise, which means $\varepsilon t$ is independent and identically distributed with mean " 0 " and variance " $\sigma^{21}$. Random walk can also be named a process integrated of some order, a process with a unit root or a process with a stochastic trend. It is a non mean reverting process that can move away from the mean either in a positive or negative direction. Another characteristic of a random walk is that the variance evolves over time and goes to infinity as time goes to infinity; therefore, a random walk cannot be predicted. The second is Random Walk with Drift $(\mathrm{Yt}=\alpha+\mathrm{Yt}-1+\varepsilon \mathrm{t})$ if the random walk model predicts that the value at time " $\mathrm{t}$ " will equal the last period's value plus a constant, or drift $(\alpha)$, 
and a white noise term (et), then the process is random walk with a drift. It also does not revert to a long-run mean and has variance dependent on time. While the third type is Deterministic Trend $(\mathrm{Yt}=\alpha+\beta \mathrm{t}+\varepsilon \mathrm{t})$ often a random walk with a drift is confused for a deterministic trend. Both include a drift and a white noise component, but the value at time " $t$ " in the case of a random walk is regressed on the last period's value (Yt-1), while in the case of a deterministic trend it is regressed on a time trend $(\beta \mathrm{t})$. A non-stationary process with a deterministic trend has a mean that grows around a fixed trend, which is constant and independent of time. The fourth type is Random Walk with Drift and Deterministic Trend ( $\mathrm{Yt}=\alpha+\mathrm{Yt}-1+\beta \mathrm{t}+\varepsilon \mathrm{t})$ another example is a non-stationary process that combines a random walk with a drift component $(\alpha)$ and a deterministic trend $(\beta \mathrm{t})$.It specifies the value at time " $\mathrm{t}$ " by the last period's value, a drift, a trend and a stochastic component. The last type is trend and Difference Stationary. A random walk with or without a drift can be transformed to a stationary process by differencing (subtracting Yt-1 from Yt, taking the difference Yt - Yt-1) correspondingly to $(\mathrm{Yt}-\mathrm{Yt}-1=\varepsilon t$ or Yt $-\mathrm{Yt}-1=\alpha+\varepsilon t)$ and then the process becomes difference-stationary. The disadvantage of differencing is that the process loses one observation each time the difference is taken.

\subsubsection{Unit-Root Test}

If there is no fixed level for the price. Then the time series is called unit-root non-stationary. The best example of unit-root non-stationary time series is the random-walk model. The theory behind ARMA estimation is based on stationary time series. A series is said to be (weakly or covariance) stationary if the mean and autocovariances of the series do not depend on time. Any series that is not stationary is said to be nonstationary.

Various definitions of non-stationarity exist as we noted above. In his section, the Researcher really referring to the weak form or covariance stationarity. There are two models which have been frequently used to characterise non-stationarity: the random walk model with $\operatorname{drift}(\mathrm{Yt}=\alpha+\mathrm{Yt}-1+\varepsilon \mathrm{t})$ and the deterministic trend process $(\mathrm{Yt}=\alpha$ $+\mathrm{Yt}-1+\beta \mathrm{t}+\varepsilon \mathrm{t})$.

To test whether the log price pt of stocks or indices follow a random walk or a random walk with a drift, we apply the models

$$
\begin{aligned}
& \mathrm{pt}=\varphi 1 \mathrm{pt}-1+\mathrm{et} \\
& \mathrm{pt}=\varphi 0+\varphi 1+\mathrm{pt}^{-1}+\mathrm{et},
\end{aligned}
$$

where et refers to the error term, and consider the null hypothesis Ho : $\varphi 1=1$ versus the alternative hypothesis Ha : $\varphi 1<1$. This is the well-known unit-root testing problem (Tsay, 2002). The Researcher will use three models to test the random walk of (PEX) there Augmented Dickey-Fuller (ADF) Test, Phillips-Perron (PP) test, and (Kwiatkowski, Phillips, Schmidt, and Shin) KPSS Test. Both the (ADF) and (PP) tests are based on a null hypothesis of a unit root (i.e., an I(1) series). The (KPSS) test is based on a null hypothesis of stationarity (i.e., an I(0) series). Consequently, the (KPSS) test can give quite different results from the (ADF) or (PP) tests, that (KPSS) test differs from the other unit root tests described here in that the series yt is assumed to be (trend-) stationary under the null.

\subsubsection{The Augmented Dickey-Fuller (ADF) Test}

$\mathrm{ADF}$ is a test for a unit root in a time series sample, it is a version of the Dickey-Fuller test for a larger and more complicated set of time series models. The ADF test statistic is not approximately t-distributed under the null hypothesis; instead, it has a certain nonstandard large-sample distribution under the null hypothesis of a unit root.

While the approximate linear decay of the sample ACF is often taken that the underlying time series is non-stationary and requires differencing, it is useful to test the evidence of non-stationarity in the data-generating mechanism. This can be tested via Considering this hypothesis testing model.

$\mathrm{Yt}=\alpha \mathrm{Yt}-1+\mathrm{Xt}$ While $\mathrm{t}=1,2, \ldots$.

where $\{\mathrm{Xt}\}$ is a stationary process. The process $\{\mathrm{Yt}\}$ is non-stationary if the coefficient $\alpha=1$, but it is stationary if $|\alpha|<1$. Suppose that $\{\mathrm{Xt}\}$ is an $\operatorname{AR}(\mathrm{k})$ process:

$$
\mathrm{Xt}=\varphi 1 \mathrm{Xt}-1+\varphi \mathrm{kXt}-\mathrm{k}+\mathrm{et} .
$$

Under the null hypothesis that $\alpha=1, \mathrm{Xt}=\mathrm{Yt}-\mathrm{Yt}-1$. Letting $\mathrm{a}=\alpha-1$, we have

$$
\begin{aligned}
\mathrm{Yt}-\mathrm{Yt}-1= & (\alpha-1) \mathrm{Yt}-1+\mathrm{Xt} \\
& =\mathrm{aYt}-1+\varphi 1 \mathrm{Xt}-1 \ldots+\varphi \mathrm{kXt}-\mathrm{k}+\mathrm{et} \\
=\mathrm{aYt}-1 & +\varphi 1(\mathrm{Yt}-1-\mathrm{Yt}-2) \ldots+\varphi \mathrm{k}(\mathrm{Yt}-\mathrm{k}-\mathrm{Yt}-\mathrm{k}-1)+\text { et. }
\end{aligned}
$$

where $\mathrm{a}=0$ under the hypothesis that $\mathrm{Yt}$ is difference non-stationary. On the other hand, if $\{\mathrm{Yt}\}$ is stationary so that $-1<\alpha<1$, then it can be verified that Yt still satisfies an equation similar to the equation above but with different 
coefficients.

\subsubsection{Phillips-Perron (PP) test}

Phillips-Perron test is used in time series analysis to test the null hypothesis that a time series is integrated of order (1), and the results are used to calculate the test statistics Phillips and Perron (1988) proposed two alternative statistics, which Perron presents. Phillips and Perron's test statistics can be reviewed as Dicky Fuller statistics that have been made robust to serial correlation by using the Newey-West (1987) heteroskedasticity- and autocorrelation-consistent covariance matrix estimator. The Phillips_Perron test involves fitting the regression

$$
y_{i}=\alpha+p y_{i-1}+\varepsilon_{i}
$$

Where we may exclude the constant or include a trend term. There are two statistics. $Z_{p}$ and $Z_{\tau}$

$$
\begin{aligned}
& \mathrm{Z}_{p}=n(\hat{p n})-\frac{1}{2} \frac{n^{2} \hat{\delta}^{2}}{S_{n}^{2}}\left(\hat{\lambda}_{n}^{2}-\hat{\gamma}_{0, n}\right)
\end{aligned}
$$

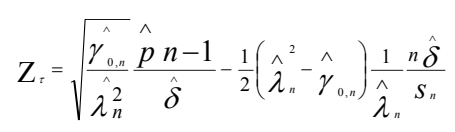

$$
\begin{aligned}
& \hat{\lambda}_{j, n}=\frac{1}{n_{i=j+1}} \sum_{u_{i}} \hat{u_{i-i}} \\
& \hat{\lambda}_{n}^{2}=\hat{\gamma}_{0, n}+2 \sum_{j=1}^{q}\left(1-\frac{j}{q+1}\right) \hat{\gamma}_{j, n} \\
& S_{n}^{2}=\frac{1}{n-k} \sum_{i=1}^{n} \hat{u}_{i}^{2}
\end{aligned}
$$

Where is the OLS residual, $\mathrm{K}$ is the number of covariates in the regression. $\mathrm{q}$ is the number of Newey _ west lags to use in calculating $\hat{\lambda}_{n}^{2}$. and $\hat{\delta}$ is the OLS standard error of $\hat{p}$. Phillips-Perron tests assess the null hypothesis of a unit root in a unvaried time series $y$. All tests use the model:

$$
y_{t}=c+d t+a y_{t-1}+e(t) .
$$

The null hypothesis restricts $a=1$. Variants of the test, appropriate for series with different growth characteristics, restrict the drift and deterministic trend coefficients, $\mathrm{c}$ and d, respectively, to be 0 . The tests use modified Dickey-Fuller statistics to account for serial correlations in the innovations process e(t) (Phillips and Perron, 1988).

\subsubsection{3 (Kwiatkowski, Phillips, Schmidt, and Shin) KPSS Test}

In econometrics, (Kwiatkowski-Phillips-Schmidt-Shin tests) KPSS (1992) test are used for testing a null hypothesis that an observable time series is stationary around a deterministic trend (Bhargava, A.1986). Such models were proposed in 1982 a test of the null hypothesis that an observable series is trend stationary (stationary around a deterministic trend). The series is expressed as the sum of deterministic trend, random walk, and stationary error, and the test is the LM test of the hypothesis that the random walk has zero variance. KPSS type tests are intended to complement unit root tests, such as the Dickey-Fuller, Phillips-Perron tests, by testing both the unit root hypothesis and the stationarity hypothesis, one can distinguish series that appear to be stationary, series that appear to have a unit root, and series for which the data (or the tests) are not sufficiently informative to be sure whether they are stationary or integrated (Kwiatkowski, et, al. 1992). Sometimes it is convenient to have stationary as the null Hypothesis. Assume there is no trend. The point of departure is a DGP of the form

$$
Y_{t}=\xi_{t}+e_{t}
$$

where et is stationary and $\xi_{\mathrm{t}}$ is a random walk, i.e.

$$
\xi_{\mathrm{t}}=\xi_{\mathrm{t}-1}+\mathrm{vt}_{\mathrm{t}} \mathrm{Vt} \sim \operatorname{IID}\left(0, \sigma_{\mathrm{v}}^{2}\right)
$$

If the variance is zero, $\sigma^{2}{ }_{v}=0$, then $\xi_{\mathrm{t}}=\xi_{0}$ for all $\mathrm{t}$ and $\mathrm{Yt}$ is stationary. Use a simple regression:

$$
\mathrm{Y}_{\mathrm{t}}=\mu+\hat{e}_{\mathrm{t}},
$$

to find the estimated stochastic component. Under the null, êt is stationary. That observation can be used to design a test:

$\mathrm{H} 0: \sigma_{\mathrm{v}}^{2}=0$ Against $\mathrm{Ha}: \sigma_{\mathrm{v}}^{2}>0$. 
The test statistic is given by

$$
K P S S=\frac{1}{\mathrm{~T}^{2}}\left(\frac{\sum_{t=1}^{\mathrm{T}} s_{i}^{2}}{\widehat{\sigma_{\infty}^{2}}}\right)
$$

Where $S_{t}=\sum_{s=1}^{\mathrm{T}} \hat{e}_{t} \quad$ is a partial sum

$\sigma^{2} \infty$ is estimator of the variance of êt. (This is an LM test for constant parameters against a RW parameter).

\subsection{Findings of The Research}

\subsubsection{Descriptive Data}

The table (3) presents general idea about the market daily series in the period from January $1^{\text {st }}, 2007$ to December $31^{\text {st }}$, 2010, for a total of 987 observations related to (PEX) indices which shows (Mean, Median, Maximum, Minimum, Standard Deviation, Skewness, and Kurtosis) for all indices in (PEX).

\subsubsection{Results of Hypothesis Testing}

In this section the Research applied the quantitative analytical method in the social sciences. This empirical study tested the stationary of the market's indices by testing the random walk of those indices, the research for this purpose used the E-views program to test the Agument Dickey fuller (ADF) test, the Phillips Perron (PP) test, which test the unit roots of drift, and the Kwiatkoowski-Phillips-Schmidt-Shin (KPSS) which are suitable in drift and trend. The Researcher applied those tests not only for the general index but also for other indices in the market (Al-Quds, Industry, banking, Investment, Insurance, and Services sectors). Applying the tests at all the indices intend to increase the accuracy of the results. The Researcher tested the random walk of the (PEX) main indices during the period from January 1st, 2007 to December 31st, 2010. The table(4) proved that the null hypothesis of unit roots for all the daily time series indices are rejected at their first differences on the (ADF) with both intercept, also with intercept and trend. Statistics values in both are less than the critical values at $10 \%, 5 \%$ and $1 \%$ levels of significance. The table(5) also give the same result of (ADF) that proved the null hypothesis of unit roots for all the daily time series indices are rejected at their first differences on the (PP) with both intercept, also with intercept and trend. Statistics values in both are less than the critical values at $10 \%, 5 \%$ and $1 \%$ levels of significance. Thus, the daily time series are stationary and integrated in the same order. Also the trend stationary test (KPSS) shows the null-hypothesis of stationary (or non-random behavior of stock price changes) can not be rejected as the $t$ test value with intercept andwith intercept and trend less than critical values at $10 \%, 5 \%$ and $1 \%$ except the Insurance sector Index in 5\%, and 10\% significance levels as shown in Table (6) which includes results of stationary test (KPSS). The results of the present study suggest that the market is weak form inefficient. This provides opportunity to the traders for predicting the future prices and earning abnormal profits.

\section{Conclusion and Recommendations}

In this research the Researcher finds that the (PEX) is an inefficient in weak form by using the analysis of all daily time series of the (PEX) indices during the Period from January 1st, 2007 to December 31st, 2010, that (ADF, PP, and KPSS) tests for the (general index, Al-Quds index and all sectoral indices) do not follow the random walk theory in $1 \%, 5 \%$, and $10 \%$ significant levels, which means the possibility of making abnormal returns by using technical analysis strategies. The findings of this research are the same as the most recent studies in emerging markets, specially in weak form which proved contrast to of what EMH proved. The previous studies differed in statistical methods and tools of testing the random walk. This research gives the same results of Falojey (2005), Gupta, and Basu (2007), Miclaus, et, al. (2008), Moldovan (2008), and Onour (2009) whom proved that their markets inefficient in weak form, and disagree with the results of Gan, et, al. (2005), Islam and Khaled (2005), Olowe (2002), and Venkatesan (2010) whom proved the efficiency in the weak form. The results were similar with Falojey (2005) which study the efficiency of (PEX) but this research excellences that had selected a series of longer time, also it had adopted more accurate and appropriate statistical indicators (ADF, PP, and KPSS). As well as the Researcher has boosted the results of a study by testing the main sectoral indices in (PEX) in addition to the general index and AL-Quds index. So the Researcher in this research recommends that the policy makers must increase the control on the (PEX) in order of protect small investors fall prey to the big investors. The investors in (PEX) must be trained at the fundamental and technical analysis. The need to encourage the brokerage companies to appoint financial analysts specialized in both technical and fundamental analysis. Finally enhancing the efforts of researchers to find out suitable strategies helping investors in making proper decisions. 


\section{References}

Besely, S. \& Brigham, E. (2003). Principles of Finance, London, south - western, $4^{\text {th }}$ Edition.

Brealey, Myers, \& Marcus. (2001). Fundamental of Corporate Finance, $3^{\text {rd }}$ edition.

Bulletin of Palestine Securities Exchange.

Dickey, D. \& Fuller W. (1979). Distribution of the Estimators for Autoregressive Time Series with a Unit Root, Journal of the American Statistical Association, 74: 427-43. http://dx.doi.org/ 10.2307/2286348

Falojy, Y. (2005). Testing the Efficiency of Palestinian Security Exchange.

Fama, E. French, K. (1997). Industry Costs of Equity, Journal of Financial Economics. 43:153-193

Fama, E. (1995). Random Walks In Stock Market Prices, Financial Analysts Journal, 51(1),75-82.

Fama, E. \& Kenneth R. (1993). Common Risk Factors in the Returns on Stocks and Bonds, Journal of Financial Economics, 33 (1): 3-56. http://dx.doi.org/ 10.1016/0304-405X(93)90023-5

Fama, E. French, K. (1993). Common Risk Factors in the Returns on Stocks and Bonds, Journal of Financial Economics, 4: 427-465

Fama, E. (1991). Efficient Capital Markets: II, The Journal of Finance, 46(5):1575-1617.

Fama, E. (1965). The Behavior of Stock-Market Prices. Journal of Business, 1965, 38(1): 34-105.

Fox, J. (2009). The Myth of the Rational Market, HarperColins Publishers.

Gan, \& Lee. (2005). Revisiting Share Market Efficiency: Evidence from the New Zealand Australia, US and Japan Stock Indices, American Journal of Applied Sciences, 2 (5): 996-1002.

Gupta, R. \& Basu P.K. (2007). Weak Form Efficiency in Indian Stock Markets, International Business \& Economics Research Journal, 6 (3): 57-64.

Harel, A., Harpaz, G. \& Francis J. (2011) Analysis of Efficient Markets, Review of Quantitative Finance and Accounting, 36 (2): 287-296. http://dx.doi.org/10.1007/s11156-010-0178-z

Islam, A. and Khaled, M. (2005). Tests of Weak-Form Efficiency of the Dhaka Stock Exchange, Journal of Business Finance \& Accounting, 32(7):1613-1624. http://dx.doi.org/10.1111/j.0306-686X.2005.00642.x

Kwiatkowski, D. Phillips, P. C. B. Schmidt, P. \& Shin Y. (1992). Testing the Null Hypothesis of Stationarity against the Alternative of a Unit Root, Journal of Econometrics, 54: 159-178. http://dx.doi.org/ 10.1016/0304-4076(92)90104-Y

Malkiel, Burton. G. (2003). The Efficient Market Hypothesis and Its Critics. Journal of Economic Perspectives, 17(1): 59-82. http://dx.doi.org/10.1257/089533003321164958

Mattar, M. (2001). Financial Investments Management, Amman Al Waraq inc, $2^{\text {nd }}$ edition.

Miclaus, P. G., Lupu, R., Dumitrescu, S.A. \& Bobirca, A. (2008). Testing the Efficiency of the European Carbon, Journal of Financial Economics, 49: $283-306$.

Mishkin, F. \& Eakins, S. (2009). Financial Markets and Institutions, Addison Wesley; $6^{\text {th }}$ Edition.

Moldovan, D. (2008). Testing the efficiency of the Romanian stock market, Romanian. Journal of Economic Forecasting, 69: (3).

Olowe, R. (2002). Weak Form Efficiency of the Nigerian Stock Market: Further evidence. African Development Review, 11(1): 54-68. http://dx.doi.org/ 10.1111/1467-8268.00003

Onour, I. (2009). Testing Efficiency Performance of Saudi Stock Market, Journal of King Abdu Aziz University, Economics and Administrative Science, 23: (2).

Phillips, P. (1988). Trends and Random Walks In Macroeconomic Time Series, Journal of Econometrica, 55: 277301.

Ross, Westerfield, and Jordan. (2003). Essentials of Corporate Finance, $4^{\text {th }}$ edition.

Treynor, J. (1981). What Does It Take to Win the Trading Game?, Financial Analysts Journal, 37: 55-60.

Tsay, R.S. (2002). Analysis of Financial Time Series, University of Chicago A Wiley-Interscience Publication, JOHN WILEY \& SONS, INC. 
Venkatesan k. (2010) Testing Random Walk Hypothesis of Indian Stock Market Returns: Evidence from the National Stock Exchange (NSE).

Wallace, C. (2010). Using Behavioral Finance to Better Understand the Psychology of Investors, The Journal of Alternative Investments.

\section{Appendix}

Table 1. The companies included in AL-Quds index

\begin{tabular}{|l|l|c|}
\hline- & Name of the Company & Symbol of the Company \\
\hline $1-$ & ARAB ISLAMIC BANK & AIB \\
\hline $2-$ & PALESTINE ISLAMIC BANK & ISBK \\
\hline $3-$ & BANK OF PALESTINE & BOP \\
\hline $4-$ & PALESTINE INDUSTRIAL INVESTMENT & PIC \\
\hline $5-$ & PALESTINE DEVELOPMENT \& INVESTMENT & PRICO \\
\hline $6-$ & PALESTINE REAL ESTATE INVESTMENT & PALTEL \\
\hline $7-$ & PALESTINE TELECOMMUNICATIONS & WASSEL \\
\hline $8-$ & PALESTINIAN DISTRIBUTION\&LOGISTICES SRVS & PEC \\
\hline $9-$ & PALESTINE ELECTRIC & BPC \\
\hline $10-$ & BIRZEIT PHARMACEUTICALS & JCC \\
\hline $11-$ & JERUSALEM CIGARETTES & AIG \\
\hline $12-$ & AHLIEA INSURANCE GROUP & \\
\hline
\end{tabular}

Source: Palestine Exchange website www.pex.ps

Table 2. Study sample-selection

\begin{tabular}{|c|c|}
\hline Index & $\begin{array}{c}\text { Number of } \\
\text { Companies }\end{array}$ \\
\hline AQUDS & 12 \\
\hline GENERAL & 46 \\
\hline SERVICES. & 12 \\
\hline BANKING & 8 \\
\hline INDUSRY & 10 \\
\hline INSURANCE & 7 \\
\hline INVESTEMENT & 9 \\
\hline
\end{tabular}

Table 3. Descriptive Data

\begin{tabular}{|c|c|c|c|c|c|c|c|}
\hline- & AQUDS & GENERAL & SERVICES & BANKING & INDUSR Y & INSURANCE & INVESTEMENT \\
\hline Mean & 54.4491 & 281.4139 & 52.90881 & 94.10881 & 61.37366 & 67.22884 & 31.97663 \\
\hline Median & 511.6900 & 266.3600 & 50.92000 & 95.35000 & 63.00000 & 55.78000 & 27.40000 \\
\hline Max. & 738.6700 & 370.0000 & 76.38000 & 117.1900 & 77.55000 & 139.4700 & 54.47000 \\
\hline Mini. & 407.3300 & 215.4300 & 33.57000 & 72.78000 & 51.23000 & 44.30000 & 21.18000 \\
\hline Std. Dev. & 72.64157 & 34.80139 & 8.291276 & 8.387741 & 6.100107 & 23.34912 & 9.055344 \\
\hline Skewness & 1.028899 & 0.943305 & 0.615176 & -0.332003 & 0.154027 & 1.523379 & 0.591204 \\
\hline Kurtosis & 2.985576 & 2.631684 & 3.292926 & 2.518452 & 2.263796 & 4.448511 & 1.967124 \\
\hline
\end{tabular}


Table 4. Augmented Dickey Fuller Tests with intercept and with intercept and trend

\begin{tabular}{|c|c|c|c|c|c|c|c|c|}
\hline \multirow{4}{*}{ Index } & \multicolumn{4}{|c|}{ Augmented Dickey fuller test with intercept } & \multicolumn{4}{|c|}{ Augmented Dickey fuller test with intercept and trend } \\
\hline & \multirow{3}{*}{ t- test } & \multirow{2}{*}{\multicolumn{3}{|c|}{$\begin{array}{c}\text { Critical Value } \\
\text { level }\end{array}$}} & \multirow{3}{*}{ t- test } & \multirow{2}{*}{\multicolumn{3}{|c|}{$\begin{array}{c}\text { Critical Value } \\
\text { Level }\end{array}$}} \\
\hline & & & & & & & & \\
\hline & & $10 \%$ & $5 \%$ & $1 \%$ & & $10 \%$ & $5 \%$ & $1 \%$ \\
\hline General & -21.53609 & \multirow{7}{*}{$\begin{array}{l}\hat{\sim} \\
\infty \\
0 \\
\curvearrowleft \\
\sim \\
i\end{array}$} & \multirow{7}{*}{$\begin{array}{l}\widehat{N} \\
\mathcal{J} \\
\infty \\
i \\
i\end{array}$} & \multirow{7}{*}{$\begin{array}{l}\stackrel{\infty}{S} \\
\stackrel{\infty}{+} \\
\dot{r}\end{array}$} & -21.53725 & \multirow{7}{*}{ 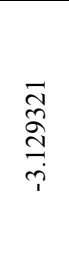 } & \multirow{7}{*}{ 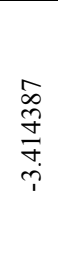 } & \multirow{7}{*}{ 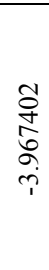 } \\
\hline Al-Quds & -21.62426 & & & & -21.61307 & & & \\
\hline Banking & -26.52504 & & & & -26.51166 & & & \\
\hline Industry & -19.18211 & & & & -30.13761 & & & \\
\hline Investment & -21.58500 & & & & -26.78333 & & & \\
\hline Insurance & -6.401273 & & & & -29.93050 & & & \\
\hline Services & -22.06220 & & & & -22.05420 & & & \\
\hline
\end{tabular}

ADF, 1different, max lag $=21$.

Table 5. Phillips Perron Tests with intercept and with intercept and trend

\begin{tabular}{|c|c|c|c|c|c|c|c|c|}
\hline \multirow{4}{*}{ Index } & \multicolumn{4}{|c|}{ Philips Perron test with intercept } & \multicolumn{4}{|c|}{ Philips Perron test with intercept and trend } \\
\hline & \multirow{3}{*}{ t- test } & \multirow{2}{*}{\multicolumn{3}{|c|}{$\frac{\text { Critical Value }}{\text { Level }}$}} & \multirow{3}{*}{ t- test } & \multirow{2}{*}{\multicolumn{3}{|c|}{$\begin{array}{c}\text { Critical Value } \\
\text { Level }\end{array}$}} \\
\hline & & & & & & & & \\
\hline & & $10 \%$ & $5 \%$ & $1 \%$ & & $10 \%$ & $5 \%$ & $1 \%$ \\
\hline General & -25.19792 & \multirow{7}{*}{$\begin{array}{l}\hat{N} \\
\infty \\
0 \\
i \\
i\end{array}$} & \multirow{7}{*}{ 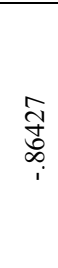 } & \multirow{7}{*}{$\begin{array}{l}\stackrel{\infty}{\delta} \\
\stackrel{\overbrace{}}{+} \\
i\end{array}$} & -25.111148 & \multirow{7}{*}{ 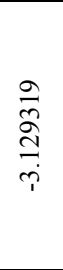 } & \multirow{7}{*}{ 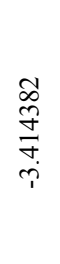 } & \multirow{7}{*}{ 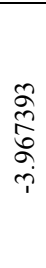 } \\
\hline Al-Quds & -25.15993 & & & & -25.06141 & & & \\
\hline Banking & -26.41365 & & & & -26.41518 & & & \\
\hline Industry & -30.06718 & & & & -30.13905 & & & \\
\hline Investment & -26.60612 & & & & -26.63963 & & & \\
\hline Insurance & -29.78874 & & & & -29.91853 & & & \\
\hline Services & -26.37690 & & & & -26.34402 & & & \\
\hline
\end{tabular}

PP 1different, max lag $=21$.

Table 6. KPSS (Kwiatkowski, Phillips, Schmidt, and Shin) Tests with intercept and with intercept and trend

\begin{tabular}{|c|c|c|c|c|c|c|c|c|}
\hline \multirow{4}{*}{ Index } & \multicolumn{4}{|c|}{ KPSS with intercept } & \multicolumn{4}{|c|}{ KPSS with intercept and trend } \\
\hline & \multirow{3}{*}{ t- test } & \multirow{2}{*}{\multicolumn{3}{|c|}{$\begin{array}{c}\text { Critical Value } \\
\text { Level }\end{array}$}} & \multirow{3}{*}{$\mathrm{t}$ - test } & \multirow{2}{*}{\multicolumn{3}{|c|}{$\begin{array}{c}\text { Critical Value } \\
\text { Level }\end{array}$}} \\
\hline & & & & & & & & \\
\hline & & $10 \%$ & $5 \%$ & $1 \%$ & & $10 \%$ & $5 \%$ & $1 \%$ \\
\hline General & 0.090860 & \multirow{7}{*}{ 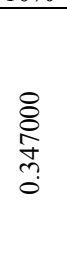 } & \multirow{7}{*}{ 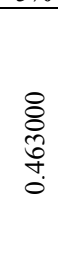 } & \multirow{7}{*}{$\begin{array}{l}\stackrel{8}{0} \\
\stackrel{\circ}{0} \\
\stackrel{0}{0}\end{array}$} & 0.087935 & \multirow{7}{*}{$\begin{array}{l}\stackrel{9}{=} \\
\overrightarrow{0}\end{array}$} & \multirow{7}{*}{$\stackrel{0}{ \pm}$} & \multirow{7}{*}{ 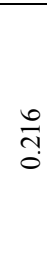 } \\
\hline Al-Quds & 0.069907 & & & & 0.069096 & & & \\
\hline Banking & 0.050053 & & & & 0.049957 & & & \\
\hline Industry & 0.272593 & & & & 0.050576 & & & \\
\hline Investment & 0.107839 & & & & 0.0649966 & & & \\
\hline Insurance & 0.593944 & & & & 0.079557 & & & \\
\hline Services & 0.089519 & & & & 0.070084 & & & \\
\hline
\end{tabular}

KPSS 1different, $\max \operatorname{lag}=21$. 